\title{
The occurrence of antibiotic-resistant bacteria, including Escherichia coli, in municipal wastewater and river water
}

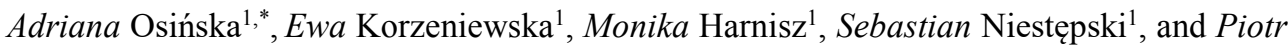 \\ Jachimowicz ${ }^{1}$ \\ ${ }^{1}$ Department of Environmental Microbiology, University of Warmia and Mazury in Olsztyn, Poland
}

\begin{abstract}
Wastewater treatment plants (WWTPs) are major reservoirs of antibiotic-resistant bacteria (ARB) which are transported to the natural environment with discharged effluents. Samples of untreated wastewater (UWW) and treated wastewater (TWW) from four municipal WWTPs and samples of river water collected upstream (URW) and downstream (DRW) from the effluent discharge point were analyzed in the study. The total counts of bacteria resistant to $\beta$-lactams and tetracyclines and the counts of antibiotic-resistant Escherichia coli were determined. Antibiotic-resistant bacteria, including antibiotic-resistant $E$. coli, were removed with up to $99.9 \%$ efficiency in the evaluated WWTPs. Despite the above, ARB counts in TWW samples were high at up to $1.25 \times 10^{5} \mathrm{CFU} / \mathrm{mL}$ in winter and $1.25 \times 10^{3} \mathrm{CFU} / \mathrm{mL}$ in summer. Antibiotic-resistant bacteria were also abundant (up to $10^{3} \mathrm{CFU} / \mathrm{ml}$ ) in URW and DRW samples collected in winter and summer. In both UWW and TWW samples, the counts of ARB and antibiotic-resistant $E$. coli were at least one order of magnitude lower in summer than in winter. The study revealed that despite the high efficiency of bacterial removal in the wastewater treatment processes, considerable amounts of ARB are released into the environment with TWW and that the percentage of ARB in total bacterial counts increases after wastewater treatment.
\end{abstract}

\section{Introduction}

Bacterial resistance to antibiotics poses a considerable challenge in medicine, and it is not limited to pathogenic microorganisms. Research studies investigating the antibiotic resistance of environmental strains revealed that the natural environment, including soil and aquatic ecosystems, are often reservoirs of clinical bacterial strains with increased resistance to antibiotics [1]. Antibiotic-resistant environmental bacteria can transfer antibiotic resistance genes (ARGs) to human pathogens, and the resulting infections are increasingly difficult or even impossible to treat with the available antibiotics [2]. Antibiotic resistance increases the prevalence of infections, often with lethal consequences.

\footnotetext{
* Corresponding author: adriana.osinska@uwm.edu.pl
} 
By limiting therapeutic options, antibiotic resistance constitutes one of the most urgent threats to public health.

Beta-lactams and tetracyclines account for approximately $95 \%$ of all antibiotics prescribed in the world. Antibiotic metabolism processes in humans and animals are considerably different, and antibiotic residues are evacuated with urine and feces into the sewage system and wastewater treatment plants (WWTPs). Prolonged exposure to even low concentrations of antibiotics in the sewage system contributes to the transfer of ARGs, exerts selective pressure on sewage-borne microorganisms [3] and leads to the spread of antibiotic resistance among bacteria in WWTPs' wastewater and in the natural environment [4].

WWTPs are significant reservoirs of bacteria, in particular gut bacteria harboring ARGs that can be transferred to other microorganisms, including environmental bacteria. Escherichia coli colonizes the gastrointestinal tract of humans and animals, and it is an important indicator of fecal contamination. Most E. coli strains are commensal bacteria, but some pathogenic strains produce enterotoxins that cause acute diarrhea and infections [5]. The presence of gut bacteria, including pathogenic and potentially pathogenic strains, in these ecosystems can exert negative effects on human and animal health. The relevant risks are heightened when these bacteria are resistant to many groups of antibiotics. Drug-resistant fecal bacteria can also confer antibiotic resistance to environmental microorganisms through horizontal gene transfer.

Activated sludge bioreactors are characterized by high concentrations of dissolved oxygen and high availability of nutrients, and they offer a supportive environment for microbial proliferation and transfer of ARGs [6]. Wastewater contains antibiotics, heavy metals, biocides and disinfectants which contribute to selective pressure and dissemination of antibiotic resistance in bacteria [7]. The effectiveness of wastewater treatment is also determined by temperature which affects bioconversion, the composition and structure of activated sludge [8,9]. Bacterial decomposition of wastewater contaminants is less effective or completely ineffective at lower temperatures. For this reason, the concentration of ammonium nitrate and the counts of nitrifying bacteria are significantly lower in winter than in summer [10]. Differences in temperature can also induce changes in the concentration of genes encoding antibiotic resistance and the efficiency of their removal [9]. Temperature influences the expression of microbial functional genes, which can promote the spread of ARGs among bacteria. The Polish climate is characterized by a broad annual temperature range (up to 60 degrees), with temperatures up to $35^{\circ} \mathrm{C}$ in summer and $-30^{\circ} \mathrm{C}$ in winter.

Antibiotic-resistant bacteria and ARGs are discharged with treated sewage and reach soils, surface water and sources of potable water. The above poses considerable health risks because ARB and ARGs evacuated to the environment can be transferred back to humans and animals $[11,12]$. Aquatic ecosystems are often subjected to strong anthropogenic pressure, which creates ideal conditions for the acquisition and spread of ARGs. Treated effluents can increase antibiotic concentrations in the aquatic environment and expose bacteria to selective pressure from antibiotics [13]. Antibiotic-resistant bacteria and ARGs can compromise the quality of drinking water, agricultural water (crop cultivation, irrigation) and water used for recreational purposes [14, 15].

The aim of this study was to compare the occurrence and counts of antibiotic-resistant bacteria, including Escherichia coli, in wastewater of municipal WWTPs in summer and winter and in samples of river water collected upstream and downstream from the effluent discharge point. 


\section{Materials and methods}

\subsection{Sampling sites and sample collection}

Samples of untreated (UWW) and treated sewage (TWW) and samples of upstream (URW) and downstream (DRW) river water were collected in four municipal WWTPs located in the Warmia and Mazury district (in total number samples: 8 of UWW, 8 of TWW, 8 of URW, 8 of DRW). The evaluated plants deploy different wastewater treatment systems based on activated sludge. Samples were collected in February 2018 and July 2018 when the consumption of antibiotics in outpatient care is highest and lowest, respectively. Samples of wastewater were collected into sterile bottles, transported to the laboratory at a temperature of $4^{\circ} \mathrm{C}$ and processed on the day of collection.

\subsection{Total bacterial counts and the counts of antibiotic-resistant bacteria}

Samples of downstream (DRW) and upstream river water (URW), untreated wastewater (UWW) and treated wastewater (TWW) were diluted with $0.85 \% \mathrm{NaCl}$ to obtain $30-300$ colony forming units (CFU) per plate. Where low bacterial counts were expected, selected URW and DRW samples were passed through a cellulose filter (filter diameter $47 \mathrm{mM}$, pore diameter $0.45 \mu \mathrm{M}$, Millipore) to obtain 8-80 CFU per filter. Greater accuracy was achieved by plating triplicates. Total bacterial counts, the counts of bacteria resistant to $\beta$-lactams (ampicillin, cefuroxime) and tetracyclines (oxytetracycline, doxycycline), total Escherichia coli counts, and the counts of Escherichia coli resistant to the above drugs were determined on plates containing TSA (Oxoid) and $\mathrm{mFc}$ agar (Merck) growth media, with or without ampicillin $(8 \mu \mathrm{g} / \mathrm{mL})$, cefuroxime $(8 \mu \mathrm{g} / \mathrm{mL})$, oxytetracycline $(16 \mu \mathrm{g} / \mathrm{mL})$ and doxycycline $(16 \mu \mathrm{g} / \mathrm{mL})$. Antimicrobial dosing was based on EUCAST guidelines [16]. The plates for the determination of total microbial counts were incubated at $30^{\circ} \mathrm{C}$ for $48 \mathrm{~h}$. E. coli were cultured at $44.5 \pm 0.2^{\circ} \mathrm{C}$ for $24 \mathrm{~h}$, and $E$. coli colonies were counted based on the number of dark blue colonies formed on $\mathrm{mFc}$ agar.

\section{Results and discussion}

In winter, the average total bacterial counts ranged from 2.30 to $8.30 \times 10^{6} \mathrm{CFU} / \mathrm{mL}$ in UWW samples and from $1.40 \times 10^{4}$ to $9.60 \times 10^{5} \mathrm{CFU} / \mathrm{mL}$ in TWW samples (Tab. 1). In summer, the average total bacterial counts were lower by at least one order of magnitude in the range of $3.50 \times 10^{4}$ to $6.85 \times 10^{5} \mathrm{CFU} / \mathrm{mL}$ in UWW samples and $8.80 \times 10^{2}$ to $8.60 \times 10^{3} \mathrm{CFU} / \mathrm{mL}$ in TWW samples. The counts of ARB were generally lower in summer than in winter, and average ARB counts in UWW samples were determined at $3.39 \times 10^{3}$ to $6.49 \times 10^{4} \mathrm{CFU} / \mathrm{mL}$ in summer and at $6.70 \times 10^{4}$ to $3.5 \times 10^{6} \mathrm{CFU} / \mathrm{mL}$ in winter. In TWW samples, ARB counts ranged from $8.7 \times 10^{1}$ to $1.25 \times 10^{3} \mathrm{CFU} / \mathrm{mL}$ in summer and from $3.10 \times 10^{3}$ to $1.25 \times 10^{5} \mathrm{CFU} / \mathrm{mL}$ in winter.

In a study by Ziembińska-Buczyńska et al., [17] total bacterial counts in activated sludge fluctuated between $12 \times 10^{9} \mathrm{CFU} / \mathrm{mL}$ in samples collected in summer and $42 \times 10^{9} \mathrm{CFU} / \mathrm{mL}$ in winter, and they increased steadily between winter and spring months. The cited authors also reported higher counts of bacteria resistant to erythromycin and sulfamethoxazole/trimethoprim in samples from winter. In winter, the predominant ARB were ampicillin-resistant bacteria that accounted for $26-91 \%$ of total bacterial counts in UWW samples, whereas summer samples of UWW were characterized by a predominance of cefuroxime-resistant bacteria (6-28\%). Summer samples of TWW were also dominated by ampicillin-resistant bacteria (15-64\%), whereas cefuroxime-resistant bacteria accounted for $8-18 \%$ of total bacterial counts in winter samples. It should be noted that the percentage of ARB in total bacterial counts after wastewater treatment decreased in winter, but 
increased significantly in summer. Osińska et al. [18] analyzed various wastewater treatment systems based on activated sludge and reported an increase in the percentage of $\mathrm{ARB}$ in total bacterial counts during the treatment process. An increase in the proportions of $\mathrm{ARB}$ in treated wastewater can be attributed to the presence of mobile genetic elements in bacterial cells, including integrons, plasmids and transposons, which play a key role in the transmission of ARGs [19-21]. The spread of ARGs among sewage-borne bacteria can also be induced by antibiotics and antibiotic degradation products which increase selective pressure on microorganisms [22]. According to Jutkina et al., [23] sublethal antibiotic concentrations not only exacerbate selective pressure, but also directly contribute to the dissemination of ARGs through horizontal gene transfer.

Table 1. Total counts of bacteria, counts of bacteria resistant to beta-lactams and tetracycline, percent of reduction and the share of antibiotic resistant bacteria in total counts of microorganisms in wastewater.

\begin{tabular}{|c|c|c|c|c|c|c|}
\hline & \multicolumn{3}{|c|}{ Summer } & \multicolumn{3}{|c|}{ Winter } \\
\hline & $\begin{array}{c}\text { UWW } \\
\text { (CFU/mL ) }\end{array}$ & $\begin{array}{c}\text { TWW } \\
(\mathrm{CFU} / \mathrm{mL})\end{array}$ & $\begin{array}{l}\% \text { of } \\
\text { reduction }\end{array}$ & $\begin{array}{c}\text { UWW } \\
(\mathrm{CFU} / \mathrm{mL})\end{array}$ & $\begin{array}{c}\text { TWW } \\
\text { (CFU/mL ) }\end{array}$ & $\begin{array}{l}\% \text { of } \\
\text { reduction }\end{array}$ \\
\hline TB & $\begin{array}{c}0.35- \\
6.85 \times 10^{5} \\
\end{array}$ & $0.88-8.6 \times 10^{3}$ & 97-99.99 & $2.3-8.3 \times 10^{6}$ & $0.14-9.6 \times 10^{5}$ & 88-99.99 \\
\hline TBA & $\begin{array}{c}0.634- \\
5.67 \times 10^{4}\end{array}$ & $\begin{array}{c}0.416- \\
1.25 \times 10^{3}\end{array}$ & \multirow{2}{*}{ 86-99.99 } & $1.65-3.5 \times 10^{6}$ & $\begin{array}{c}0.165- \\
1.25 \times 10^{5}\end{array}$ & \multirow{2}{*}{ 94-99.99 } \\
\hline$\%$ ARB & $1-18 \%$ & $15-64 \%$ & & $26-91 \%$ & $12-17 \%$ & \\
\hline TBC & $\begin{array}{c}0.956- \\
5.68 \times 10^{4} \\
\end{array}$ & $\begin{array}{c}0.087- \\
1.25 \times 10^{3} \\
\end{array}$ & \multirow[t]{2}{*}{$96-99.65$} & $0.53-1.1 \times 10^{6}$ & $\begin{array}{c}0.175- \\
1.03 \times 10^{5}\end{array}$ & \multirow[t]{2}{*}{$90-99.77$} \\
\hline$\%$ ARB & $6-28 \%$ & $10-20 \%$ & & $8-43 \%$ & $8-18 \%$ & \\
\hline TBO & $\begin{array}{c}0.829- \\
6.49 \times 10^{4} \\
\end{array}$ & $2.3-4.56 \times 10^{2}$ & \multirow[t]{2}{*}{ 94-99.47 } & $0.67-9.0 \times 10^{5}$ & $\begin{array}{l}0.545- \\
1.1 \times 10^{4} \\
\end{array}$ & \multirow[t]{2}{*}{ 83-99.94 } \\
\hline$\% \mathrm{ARB}$ & $2-25 \%$ & $3-52 \%$ & & $1-14 \%$ & $1-8 \%$ & \\
\hline TBD & $3.39-6.5 \times 10^{3}$ & $1.2-4.6 \times 10^{2}$ & \multirow[t]{2}{*}{$92-96.46$} & $\begin{array}{c}0.93- \\
1.26 \times 10^{6} \\
\end{array}$ & $\begin{array}{c}0.31- \\
1.97 \times 10^{4} \\
\end{array}$ & \multirow[t]{2}{*}{$98-99.74$} \\
\hline$\%$ ARB & $1-15 \%$ & $5-43 \%$ & & $1-15 \%$ & $1-3 \%$ & \\
\hline
\end{tabular}

CFU - colony forming unit, UWW - untreated wastewater, TWW - treated wastewater, TB - counts of total bacteria, TBA - counts of bacteria resistant to ampicillin, TBC - counts of bacteria resistant to cefuroxime, TBO - counts of bacteria resistant to oxytetracycline, TBD - counts of bacteria resistant to doxycycline, $\%$ ARB- the share of antibiotic resistant bacteria in total counts of microorganism

Total bacterial counts and ARB counts were reduced and characterized by similar proportions in TWW samples collected both in summer and winter. Total bacterial counts and ARB counts were reduced by $86.06-99.9 \%$ in summer and by $83.58-99.99 \%$ in winter. In the work of Czekalski et al. [11] and Korzeniewska and Harnisz [24], bacterial counts were reduced in TWW, but the the presence of multidrug resistant strains and an increase in the counts of ARGs were observed in discharged effluents. Proia et al., [25] also reported a significant reduction in the abundance of ARB, but did not note significant differences in ARB counts after wastewater treatment. In a study by Bodnarczuk et al., [26] wastewater treatment led to a significant decrease in the counts of heterotrophic bacteria (by up to two orders of magnitude). Despite the above, the counts of ampicillin-resistant bacteria increased in lake sediments, which could point to the spread of ARB in the environment.

In winter, the average total bacterial counts ranged from $2.33 \times 10^{3}$ to $1.10 \times 10^{4} \mathrm{CFU} / \mathrm{mL}$ in URW samples and from 2.20 to $9.20 \times 10^{3} \mathrm{CFU} / \mathrm{mL}$ in DRW samples (Tab. 2). In summer, the average total bacterial counts were determined in the range of $3.60 \times 10^{3}-1.24 \times 10^{4} \mathrm{CFU} / \mathrm{mL}$ in URW samples and $4.20 \times 10^{3}-1.23 \times 10^{4} \mathrm{CFU} / \mathrm{mL}$ in DRW samples. 
Table 2. Total counts of bacteria, counts of bacteria resistant to beta-lactams and tetracycline, percent of reduction and the share of antibiotic resistant bacteria in total counts of microorganisms in river water/

\begin{tabular}{|c|c|c|c|c|}
\hline \multirow{2}{*}{} & \multicolumn{2}{|c|}{ Summer } & \multicolumn{2}{c|}{ Winter } \\
\cline { 2 - 5 } & URW & DRW & URW & DRW \\
\hline TB & $0.36-1.24 \times 10^{4}$ & $0.42-1.23 \times 10^{4}$ & $0.233-1.1 \times 10^{4}$ & $2.2-9.2 \times 10^{3}$ \\
\hline TBA & $0.28-4.56 \times 10^{3}$ & $0.28-4.9 \times 10^{3}$ & $1.4-3.76 \times 10^{3}$ & $1.8-6.7 \times 10^{3}$ \\
\hline$\%$ ARB & $8-47 \%$ & $7-41 \%$ & $30-67 \%$ & $1-89 \%$ \\
\hline TBC & $0.18-3.2 \times 10^{3}$ & $0.19-3.4 \times 10^{3}$ & $1.74-2.89 \times 10^{3}$ & $1.45-4.78 \times 10^{3}$ \\
\hline$\%$ ARB & $5-33 \%$ & $5-28 \%$ & $24-75 \%$ & $1-72 \%$ \\
\hline TBO & $0.09-1.8 \times 10^{3}$ & $0.095-1.4 \times 10^{3}$ & $0.003-2.86 \times 10^{3}$ & $0.065-1.27 \times 10^{3}$ \\
\hline$\%$ ARB & $3-18 \%$ & $2-12 \%$ & $0.13-26 \%$ & $0.007-32 \%$ \\
\hline TBD & $0.15-1.4 \times 10^{2}$ & $0.3-2.0 \times 10^{1}$ & $0.05-1.6 \times 10^{2}$ & $0.5-6.5 \times 10^{1}$ \\
\hline$\%$ ARB & $0.2-1 \%$ & $0.1-0.2 \%$ & $0.21-1 \%$ & $0.047-0.38 \%$ \\
\hline
\end{tabular}

URW - upstream river water, DRW - downstream river water, remainder explanation of abbreviations under Table1

The absence of a reduction in bacterial counts in summer samples of river water relative to winter samples could be associated with the specific character of sampling sites and their surroundings (allotment gardens, forests and urban areas). In URW samples, ARB counts ranged from $1.5 \times 10^{1}$ to $4.56 \times 10^{3} \mathrm{CFU} / \mathrm{mL}$ in summer and from $3 \times 10^{0}$ to $3.76 \times 10^{3} \mathrm{CFU} / \mathrm{mL}$ in winter. In DRW samples, ARB counts were determined in a range of $3 \times 10^{0}-4.90 \times 10^{3}$ $\mathrm{CFU} / \mathrm{mL}$ in summer and $5 \times 10^{0}-6.7 \times 10^{3} \mathrm{CFU} / \mathrm{mL}$ in winter. Samples of URW collected in both winter and summer were characterized by a predominance of ampicillin-resistant bacteria (up to $67 \%$ and $47 \%$ of total bacterial counts, respectively) and cefuroxime-resistant bacteria (up to $75 \%$ and $33 \%$, respectively). A predominance of ampicillin- and cefuroxime-resistant bacteria was also noted in DRW samples where these microorganisms accounted up to $89 \%$ and $72 \%$ of total bacterial counts, respectively, in winter, and $41 \%$ and $28 \%$ of total bacterial counts, respectively, in summer. Doxycyclineresistant bacteria were least prevalent in URW and DRW samples (less than $1 \%$ of total bacterial counts) in both seasons. In most DRW samples collected in winter, the percentage of bacteria resistant to ampicillin, cefuroxime and oxytetracycline increased relative to URW samples. In contrast, the proportions of ARB in most DRW samples collected in summer decreased relative to URW samples collected in the same season. Similar results were reported in a study by Harnisz et al., [27] total bacterial counts were determined at up to $1.5 \times 10^{3} \mathrm{CFU} / \mathrm{mL}$ in URW samples and $3.1 \times 10^{3} \mathrm{CFU} / \mathrm{mL}$ in DRW samples. They observed that the counts of bacteria resistant to oxytetracycline and doxycycline ranged from $3 \times 10^{1}$ to $1.0 \times 10^{2} \mathrm{CFU} / \mathrm{mL}$ in URW samples and from $3.0 \times 10^{1}$ to $2.0 \times 10^{2} \mathrm{CFU} / \mathrm{mL}$ in DRW samples. Proia et al., [25] reported an increase in E. coli counts in DRW samples where total bacterial counts were determined at $10^{8} \mathrm{CFU} / \mathrm{L}$. In the cited study, the abundance of ARGs was relatively high in URW samples, and it increased significantly in DRW samples, which indicates that urban activities contribute to the dissemination of antibiotic resistance. Xu et al., [13] also reported a high percentage of ARB in river water and bottom sediments. Samples of river water were abundant not only in ARB and ARGs, but also in antibiotics and antibiotic degradation products, which suggests that effluents discharged to rivers can substantially promote antibiotic resistance. Osińska et al., [28] isolated multidrug resistant E. coli from DRW samples (32\% of isolates), but not from URW samples.

In winter, the average total $E$. coli counts ranged from $1.85 \times 10^{4}$ to $6.45 \times 10^{5} \mathrm{CFU} / \mathrm{mL}$ in UWW samples and from $2.5 \times 10^{1}$ to $1.55 \times 10^{3} \mathrm{CFU} / \mathrm{mL}$ in TWW samples (Tab. 3). 
Table 3. Total counts of Escherichia coli, counts of Escherichia coli resistant to beta-lactams and tetracycline, percent of reduction and the share of antibiotic resistant bacteria in total counts of microorganisms in wastewater.

\begin{tabular}{|c|c|c|c|c|c|c|}
\hline & \multicolumn{3}{|c|}{ Summer } & \multicolumn{3}{|c|}{ Winter } \\
\hline & $\begin{array}{c}\text { UWW } \\
(\mathrm{CFU} / \mathrm{mL})\end{array}$ & $\begin{array}{c}\text { TWW } \\
(\mathrm{CFU} / \mathrm{mL})\end{array}$ & $\begin{array}{c}\% \text { of } \\
\text { reduction }\end{array}$ & $\begin{array}{c}\text { UWW } \\
(\mathrm{CFU} / \mathrm{mL})\end{array}$ & $\begin{array}{c}\text { TWW } \\
(\mathrm{CFU} / \mathrm{mL})\end{array}$ & $\begin{array}{l}\% \text { of } \\
\text { reduction }\end{array}$ \\
\hline EC & $2.2-7.59 \times 10^{3}$ & $\begin{array}{c}0.11- \\
4.5 \times 10^{2} \\
\end{array}$ & $82-99.86$ & $\begin{array}{c}0.185- \\
6.45 \times 10^{5} \\
\end{array}$ & $\begin{array}{c}0.025- \\
1.55 \times 10^{3} \\
\end{array}$ & 9-99.99 \\
\hline ECA & $2.75-9.95 \times 10^{2}$ & $\begin{array}{c}0.65- \\
8.7 \times 10^{1} \\
\end{array}$ & \multirow[t]{2}{*}{ 75-99.35 } & $\begin{array}{c}0.351- \\
2.75 \times 10^{4} \\
\end{array}$ & $\begin{array}{c}0.065- \\
2.4 \times 10^{2} \\
\end{array}$ & \multirow[t]{2}{*}{ 93-99.93 } \\
\hline$\%$ ARB & $9-27 \%$ & $19-59 \%$ & & $2-56 \%$ & $15-39 \%$ & \\
\hline ECC & $0.19-1.35 \times 10^{3}$ & $0.2-5.6 \times 10^{1}$ & \multirow[t]{2}{*}{ 95-99.7 } & $\begin{array}{c}0.190- \\
1.35 \times 10^{3}\end{array}$ & $\begin{array}{c}0.2- \\
8.75 \times 10^{1} \\
\end{array}$ & \multirow[t]{2}{*}{$93-99.67$} \\
\hline$\%$ ARB & $3-61 \%$ & $2-22 \%$ & & $0.03-7 \%$ & $1-10 \%$ & \\
\hline ECO & $2.2-3.75 \times 10^{2}$ & $0.4-1.2 \times 10^{1}$ & \multirow[t]{2}{*}{ 94-98.67 } & $\begin{array}{c}0.29- \\
2.20 \times 10^{4}\end{array}$ & $4-1.45 \times 10^{1}$ & \multirow{2}{*}{$\begin{array}{l}99.7- \\
99.93\end{array}$} \\
\hline$\%$ ARB & $4-14 \%$ & $1-67 \%$ & & $0.45-63 \%$ & $0.48-34 \%$ & \\
\hline ECD & $1.5-5.25 \times 10^{2}$ & $\begin{array}{c}0.35- \\
3.5 \times 10^{1} \\
\end{array}$ & \multirow[t]{2}{*}{ 88-99.33 } & $1.5-9.25 \times 10^{3}$ & $\begin{array}{c}0.035- \\
1.55 \times 10^{2}\end{array}$ & \multirow[t]{2}{*}{$95-99.96$} \\
\hline$\%$ ARB & $7-13 \%$ & $8-56 \%$ & & $1-18 \%$ & $10-42 \%$ & \\
\hline
\end{tabular}

CFU - colony forming unit, UWW - untreated wastewater, TWW - treated wastewater, EC - counts of total $E$. coli, ECA - counts of E. coli resistant to ampicillin, ECC - counts of E. coli resistant to cefuroxime, ECO - counts of $E$. coli resistant to oxytetracycline, ECD - counts of $E$. coli resistant to doxycycline, \%ARB - the share of antibiotic resistant E. coli in total counts of E.coli

Similarly to total bacterial counts, the average total counts of E. coli were at least one order of magnitude smaller in summer than in winter, ranging from $2.2 \times 10^{3}$ to $7.59 \times 10^{3} \mathrm{CFU} / \mathrm{mL}$ in UWW samples collected in summer and from $1.85 \times 10^{4}$ to $6.45 \times 10^{5} \mathrm{CFU} / \mathrm{mL}$ in UWW samples collected in winter. In TWW samples, the counts of antibiotic-resistant $E$. coli were determined in the range of $2 \times 10^{0}$ to $8.7 \times 10^{1} \mathrm{CFU} / \mathrm{mL}$ in summer and $2 \times 10^{0}$ to $2.4 \times 10^{2} \mathrm{CFU} / \mathrm{mL}$ in winter. In a study investigating the prevalence of bacteria of the family Enterobacteriaceae, Korzeniewska et al., [29] found that despite a $99 \%$ reduction in these bacterial counts during wastewater treatment, bacterial abundance in discharged wastewater was high at $0.6-3.5 \times 10^{4} \mathrm{CFU} / \mathrm{mL}$. Proia et al., [25] also reported a decrease in E. coli counts from $6.0 \pm 4.4 \cdot 10^{4} \mathrm{CFU} / \mathrm{mL}$ to $7.1 \pm 7 \cdot 10^{2} \mathrm{CFU} / \mathrm{mL}$ and from $8.7 \pm 3.0 \cdot 10^{4} \mathrm{CFU} / \mathrm{mL}$ to $7.1 \pm 7.0 \cdot 10^{2} \mathrm{CFU} / \mathrm{mL}$ in treatment of wastewater in two WWTPs, whereas the reduction in the counts of antibiotic-resistant $E$. coli was significantly lower at around $2 \mathrm{log}$. Despite the observed decrease in the abundance of E. coli, antibiotic resistance was not diminished, and the counts of antibiotic-resistant $E$. coli were high (approx. $10^{2} \mathrm{CFU} / \mathrm{mL}$ ) in TWW samples. In our study observed that in winter, UWW samples were characterized by a predominance of oxytetracycline-resistant $E$. coli strains which accounted for $0.45-63 \%$ of total $E$. coli counts, whereas in TWW samples ampicillin-resistant bacteria represented $15-39 \%$ of $E$. coli strains and doxycycline- resistant bacteria represented $10-42 \%$ of $E$. coli strains. In summer, cefuroxime-resistant bacteria accounted for 3-61\% of total E. coli counts in UWW samples, whereas ampicillin-resistant and oxytetracycline-resistant $E$. coli were predominant (respectively $19-59 \%$ and $1-67 \%$ ) in TWW samples. Total E. coli counts and the counts of antibiotic-resistant $E$. coli were reduced during wastewater treatment in all analyzed plants. Total E. coli counts and the abundance of antibiotic-resistant E. coli were reduced by $75-99.86 \%$ in summer and $91-99.99 \%$ in winter. In a study by Mokracka et al., [30] the counts of ARB and E. coli decreased by $59-99 \%$ after treatment. In contrast, Osińska et al., [18] reported an increase in the counts of antibiotic-resistant E. coli after 
wastewater treatment in selected plants. The increase in the counts of antibiotic-resistant E. coli could be attributed to horizontal gene transfer between bacterial strains [29, 31].

The discharge of wastewater after the treatment process to aquatic ecosystems is an important problem from both the economic point of view and also from environmental safety. Although the applied wastewater treatment processes allow reducing the number of bacteria up to $99 \%$, in discharged wastewater from WWTPs, there may still be up to several thousand to one million coliform bacteria cells in $100 \mathrm{ml}$ of treated wastewater [24, 25, 27]. Similarly, the results presented in this article indicate significant amounts of the total number of bacteria and ARB in wastewater flowing out of WWTPs. It is important to underline that, in this article were analyzed WWTPs which took only municipal wastewater. Nevertheless, significant amounts of bacteria resistant to both older generation antibiotics (ampicillin, oxytetracycline) and newer generation antibiotics (cefuroxime, doxycycline) were found in WWTPs' effluents. Moreover, obtained results of the study indicate significant amounts of the total number of Escherichia coli and antibiotic-resistant E. coli in both untreated wastewater as well as in treated wastewater. E.coli belongs to a group of bacteria that, because of its plastic genome, are often used to monitor the spread of antibiotic resistance in various environments. The presence in the aquatic ecosystems of intestinal bacteria, originating from WWTPs, may have a negative impact on public health because of these bacteria can be characterized by multi-drug resistance and they frequently possess ARGs or virulence genes [11,28]. Additionally, these ARB can transmit resistance to native bacteria from the environment, including both pathogenic or non-pathogenic bacteria, mediated by mobile genetic elements, such as plasmids (conjugation), bacteriophages (transduction), or free DNA from the environment (transformation) [11, 17]. The obtained results indicate the presence of ARB also in river water before and after the inflow of WWTPs, which may pose a threat to human health and animals using water resources. Thus, antibiotic-resistant environmental bacteria can be a natural reservoir for the further spread of ARGs in the environment. The results of other authors also suggest that wastewater flowing into surface water is the main source of ARB and ARGs in the environment $[11,25]$. It is also worth emphasizing that in WWTPs in Poland, the processes of wastewater disinfection prior to their discharge into the environment are not commonly used. Wastewater disinfection processes could be used as potential tools to reduce the spread of ARB and ARGs to the environment. Therefore, it seems to be particularly important to monitor the effectiveness of wastewater treatment processes and the microbiological quality of wastewater discharged from WWTPs to the natural environment.

\section{Conclusions}

The results of this study indicate that wastewater treatment plants are major reservoirs of antibiotic-resistant bacteria which are evacuated to water bodies with treated effluents, thus contributing to the spread of antibiotic resistance in the natural environment. Antibiotic-resistant bacteria were effectively removed in all evaluated WWTPs. Despite the above, ARB counts continued to be high in discharged wastewater. In UWW and TWW samples, the counts of ARB and antibiotic-resistant E. coli were at least one order of magnitude lower in summer than in winter, but the percentage of ARB in total bacterial counts increased after treatment. Antibiotic-resistant bacteria were also highly abundant (up to $10^{3} \mathrm{CFU} / \mathrm{ml}$ ) in river water sampled upstream and downstream from the effluent discharge point in winter and in summer. These findings indicate that wastewater evacuated from wastewater treatment plants should be closely monitored to minimize the spread of $\mathrm{ARB}$ in the environment. 
We would like to thank the staff of the WWTPs in Białuty, Dobre Miasto,Gietrzwałd and Dobre Miasto for the possibility of samples collecting. This study was supported by grant No. UMO-2016/23/N/NZ9/02150 from the National Science Center (Poland).

\section{References}

1. R. L. Finley, P. Collignon, D. G. Larsson, S. A. McEwen, X. L. Li, W. H. Gaze, R. Reid-Smith, M. Timinouni, D. W. Graham, E. Topp, Clin. Inf. Dis. 57, 5 (2013)

2. World Health Organization. Antimicrobial Resistance: Global Report on Surveillance 2014. Available online: http://www.who.int/en/ (accessed on 6 February 2017)

3. A. Novo, S. André, P. Viana, O. Nunes, C. Manaia, Water Res. 47, 5 (2013)

4. X-X. Zhang, T. Zhang, H. H. P. Fang, Appl. Microbiol. Biotechnol. 82, (2009)

5. L. J. Dubreuil, S. Mahieux, C. Neut, C. Miossec, J. Pace, Int. J. Antimicrob. Ag. 39, $6(2012)$

6. A. Luczkiewicz, K. Jankowska, R. Bray, E. Kulbat, B. Quant, A. Sokolowska, K. Olanczuk-Neyman, Water Sci. Technol. 64, 12 (2011)

7. L. Rizzo, C. Manaia, C. Merlin, T. Schwartz, C. Dagot, M. C. Ploy, I. Michael, D. Fatta Kassinos, Sci. Total Environ. 447 (2013)

8. A. Karkman, T. A. Johnson, C. Lyra, R. D. Stedtfeld, M. Tamminen, J. M. Tiedje, M. Virta, FEMS Microbiol. Ecol. 92, 3 (2016)

9. Y. N. Jiao, Z. C. Zhou, T. Chen, Y. Y. Wei, J. Zheng, R. X. Gao, Environ. Pollut. 234 (2018)

10. T. F. Ducey, M. B. Vanotti, A. D. Shriner, A. A. Szogi, A. Q. Ellison, Bioresource Technol. 101, 2 (2010)

11. N. Czekalski, T. Berthold, S. Caucci, A. Egli, H. Bürgmann, Front. Microbiol. 3 (2012)

12. Y.-G. Zhu, T. A. Johnson, J.-Q. Su, M. Qiao, G.-X. Guo, R. D. Stedtfeld, S. A. Hashsham, J. M. Tiedje, PNAS, 110 (2013)

13. Y. Xu, C. Guo, Y. Luo, J. Lv, Y. Zhang, H. Lin, L. Wang, J. Xu, Environ. Pollut. 213 (2016)

14. J. Xu, Y. Xu, H. Wang, C. Guo, H. Qiu, Y. He, Y. Zhang, X. Li, W. Meng, Chem. 119 (2015)

15. Y. Yang, B. Li, S. C. Zou, H. H. P. Fang, T. Zhang, Water Res. 62 (2014)

16. EUCAST, European Committee on antimicrobial susceptibility testing. Breakpoints tables for interpretation of MICs and zones diameters. Version 4.0, http://www.eucast.org (2014)

17. A. Ziembińska-Buczyńska, E. Felis, J. Folkert, A. Meresta, D. Stawicka, A. Gnida, J. Surmacz-Górska, Arch. Environ. Protect. 41, 4 (2015)

18. A. Osińska, E. Korzeniewska, M. Harnisz, S. Niestępski, E3S Web Conf. 17 (2017)

19. S. Xia, L. Duan, Y. Song, J. Li, Y. M. Piceno, G. L. Andersen, L. Alvarez-Cohen, I. Moreno-Andrade, C.-L. Huang, S. W. Hermanowicz, Environ. Sci.Technol. 44, 19 (2010)

20. J. Mokracka, R. Koczura, A. Kaznowski, Water Res. 46, 10 (2012)

21. W. Xu, G. Zhang, X. Li, S. Zou, P. Li, Z. Hu, J. Li, Water Res. 41, 19 (2007)

22. Y. Y. Zhang, J. J. Geng, H. J. Ma, H. Q. Ren, K. Xu, L. L. Ding, Sci. Total Environ. $571(2016)$ 
23. J. Jutkina, N. P. Marathe, C.-F. Flach, D. G. J. Larsson, Sci. Total Environ. 616-617 (2018)

24. E. Korzeniewska, M. Harnisz, Sci. Total Environ. 639 (2018)

25. L. Proia, A. Anzil, J. Subirats, C. Borrego, M. Farrè, M. Llorca, J. L. Balcázar, P. Servais, Sci. Total Environ. 628-629 (2018)

26. K. Bondarczuk, Z. Piotrowska-Seget, Sci. Total Environ. 650 (2019)

27. M. Harnisz, E. Korzeniewska, I. Gołaś, Chem. 128 (2015)

28. A. Osińska, E. Korzeniewska, M. Harnisz, S. Niestępski, Sci. Total Environ. 577 (2017)

29. E. Korzeniewska, M. Harnisz, J. Environ. Manage. 128 (2013)

30. J. Mokracka, R. Koczura, A. Kaznowski, Water Res. 46, 10 (2012)

31. A. Osińska, M. Harnisz, E. Korzeniewska, Environ. Sci. Pollut. Res. 23, 11 (2016) 